\title{
Use of irrigation in early potatoes cultivation in the Moscow region
}

\author{
Irina Gasparyan*, Marina Dyikanova, Alexander Levshin, Basil Sudenko, and Olga Ivashova \\ Russian State Agrarian University - Moscow Timiryazev Agricultural Academy, 127550 Moscow, Russia
}

\begin{abstract}
Early potatoes are mainly used for food. In tubers varieties early term maturation contains less starch, but they differ a good taste. Getting the potato harvest in the early days, when the range of domestic vegetables is not large is very important and can compete with imports. Potatoes have increased requirements for soil moisture. The transpiration coefficient of potatoes varies depending on meteorological factors, agro-technical measures, as well as on the varietal properties of the plant itself. Getting the potato harvest in the early days, when the range of domestic vegetables is not large is very important and can compete with imports. Potatoes increased the requirements for soil moisture. The risk of potato cultivation from uneven rainfall distribution during the growing season and from the difference in years can be reduced by using irrigation. Early potatoes, while ensuring all factors manages to give a good harvest on July 15 at harvest 30 July high yield. The use of irrigation can increase yields by 50.0-55.1\% depending on the term of harvesting tubers.
\end{abstract}

\section{Introduction}

Early potatoes are mainly used for food. The recommended daily intake is approximately $300 \ldots 400 \mathrm{gr}$, which provides $10 \%$ of the physiological calorie requirement. According to some scientists [1], the content of vitamin $\mathrm{C}$ in freshly harvested potatoes is 2 ...3 times higher than in tubers after long-term storage. Vitamin $\mathrm{C}$ is found a lot in the upper layers of the tuber, closer to the peel (periderm) and is used as a food during the harvesting period, when the peel is young and easy to clean, more effective as it contains more nutrients. Earlygrowing tubers contain less starch, but they have a good taste. Getting the crop in the early stages is very important when the assortment of domestic vegetables is not large.

Potatoes have high requirements for soil moisture due to its chemical composition (about $75 \ldots 80 \%$ of its mass is water), a large vegetative mass and the harvest of tubers. The transpiration coefficient in potatoes varies depending on meteorological factors, agro-technical measures, as well as on the varietal properties of the plant itself.

The values of transpiration coefficients for potatoes, obtained by individual researchers, range from $230 \ldots 700$ [2]. For conditions of the middle band, the transpiration coefficient of potatoes is $300 \ldots 450$. With a lack and excess of moisture in the soil, the water consumption for the formation of a unit of dry matter increases. To obtain a crop of $250 \ldots 300 \mathrm{c} / \mathrm{ha}$, the water consumption is $1500 \ldots 3000 \mathrm{t} / \mathrm{ha}[3]$.

The need for moisture also changes in the phases of development. Before the emergence of seedlings, the need for plants in moisture is not large, since it is used in moisture in the mother tuber. The highest demand is noted during the period of "budding - mass flowering", due to the maximum evaporating surface of the leaves. Insufficient soil moisture during this period affects the size of tubers and yield (up to $50 \ldots 60 \%$ ) [4].

The volume of imports of food potatoes to Russia in 2018 was at the level of 755.7 thousand tons, which is $10.2 \%$ (86.3 thousand tons) less than in 2017 (Fig. 1, 2). Over 5 years of delivery increased by 57.8 per cent (on 276.8 thousand tons) 10 years $-35.9 \%$ (199.6 thousand tons). Compared to January-April 2018, volumes decreased by $64.7 \%$ (by 250.5 thousand tons). By country of origin, potato imports to Russia are presented below.

In the first place in the import of potatoes to Russia is Egypt (46.5\% of the total supply flow). The volume of imports from this country in 2018 amounted to 351.5 thousand tons, which is $8.5 \%$ (27.5 thousand tons) more than a year earlier.

Next is Belarus (34.3\%). The volume of import amounted to 259.2 thousand tons, which is 95.9 thousand tons less than in 2017. Azerbaijan's import is $8.5 \%-64.0$ thousand tons ( $12.1 \%$ growth), China $7.0 \%$ (53.2 thousand tons-a decrease of $28.3 \%$ ), Pakistan $-2.4 \%$ (18.3 thousand tons-an increase of $390.9 \%$ ). Total deliveries of potatoes in 2018 from countries not included in the TOP 5 suppliers amounted to 9.5 thousand tons (1.3\% of total imports).

The main countries-suppliers of potatoes to Russia in January-April 2019: Egypt-59.4 thousand tons (decrease in supplies compared to January-April 2018 amounted to $75.6 \%$ ) and Belarus - 54.3 thousand tons (deliveries

* Corresponding author: irina150170@yandex.ru 
decreased by $53.4 \%$ ). Using irrigation in potato cultivation technology it is possible to obtain domestic products. The main consumer is Moscow and the Moscow region, where it is possible to successfully grow domestic potatoes.

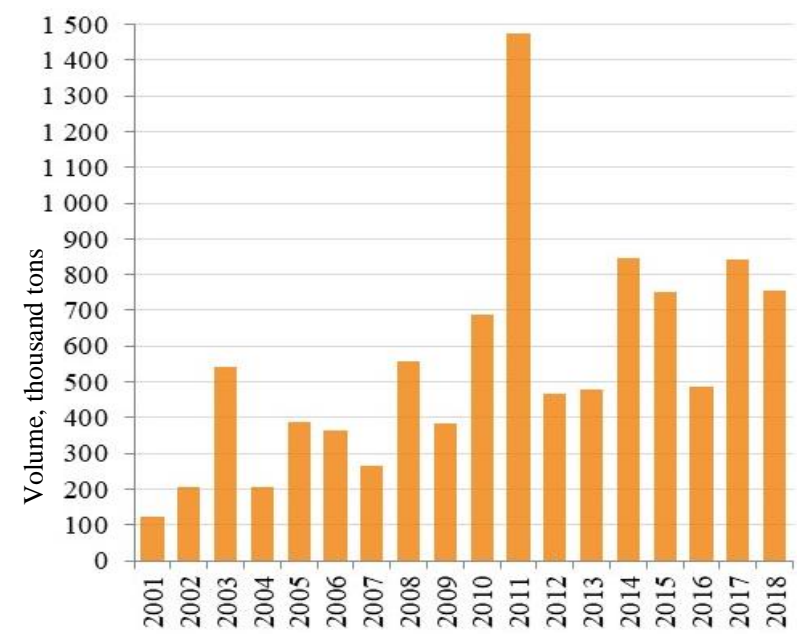

Fig. 1. Import of ware potatoes to Russia

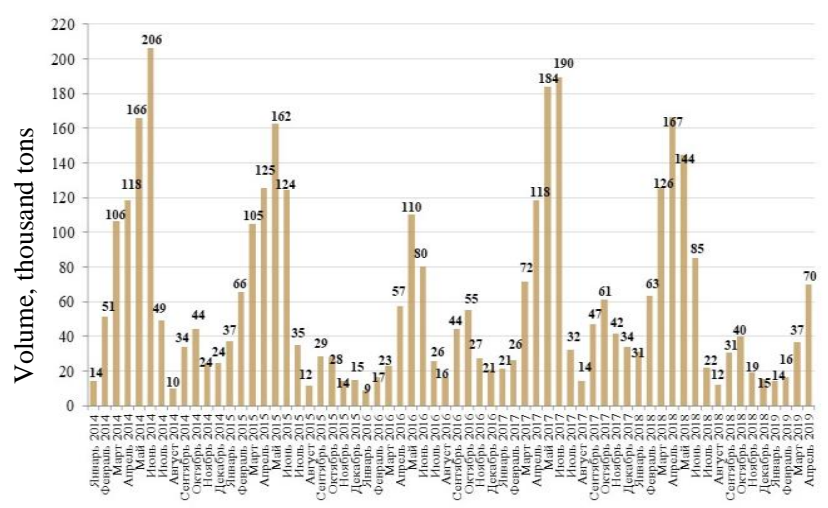

Fig. 2. Dynamics of imports of food potatoes to Russia in 2014-2019 by month, thousand tons

The Moscow region is located in a zone of sufficient moisture; precipitation averages $350 \ldots 700 \mathrm{~mm}$ per year. Precipitation is uneven in months. In recent years, sharp changes in temperature, humidity, heavy rainfall and drought are increasingly common. Providing moisture during periods when maximum moisture demand is observed is an important technique for increasing yields. Studying the effect of irrigation on the productivity of early potatoes and obtaining early products is an important task for our country. Irrigation will improve the soil moisture regime and create optimal conditions for the development of early potatoes.

\section{Methodology}

The studies were carried out in 2018-2019 on the site of the laboratory of vegetable growing RGAU-MSHA named after K.A. Timiryazev. Soils are soddy-podzolic heavy loamy, the thickness of the arable layer is $20 \ldots 22 \mathrm{~cm}$, easily hydrolyzed nitrogen is $14.0 \mathrm{mg}$ per $100 \mathrm{~g}$ of soil, phosphorus - 16.0, potassium - $20 \mathrm{mg}$ per $100 \mathrm{~g}$ of soil.
The repetition of experiments is 3 times. Variants in the experiment were placed by a randomized method. The area of one experimental plot is $25 \mathrm{~m}^{2}$. Planting scheme $-70 \times 35 \mathrm{~cm}$. The variety Luck was used. Planting was carried out at a time when the soil was warmed up to $6 \ldots 8{ }^{\circ} \mathrm{C}$. Drop watering was $5 \ldots 6 \mathrm{~mm}$ per 1 plant. The cultivation technology is standard. Cleaning was carried out in two terms: July 15 and 30.

\section{Results and discussion}

Potato yields are highly dependent on moisture availability. The total water consumption of potatoes is calculated by the formula: $\mathrm{EO}=104 \sum \mathrm{Q} / \mathrm{Ti}$. For example, during the growing season of late-maturing potato varieties from May 1 to August 1, the total PHAR arrival is $90.8 \mathrm{~kJ} / \mathrm{cm}^{2}$ [5]. Under the condition of costs $2453 \mathrm{~kJ}$ of energy for evaporation of $1 \mathrm{~kg}$ of water for this period the total water consumption reaches

$$
\mathrm{SW}=\left(10^{4} \cdot 90.8^{2} \mathrm{~kJ} / \mathrm{cm}^{2}\right) / 2453 \mathrm{~kJ} / \mathrm{kg}=370 \mathrm{~mm} \text {, }
$$$$
\text { or } 3701 \mathrm{~m}^{3} / \mathrm{ha} \text {. }
$$

Early maturing varieties evaporate $370 \mathrm{~mm}$ of water.

According to the formula: $\mathrm{EO}=\mathrm{K} \sum \mathrm{t}^{\circ}$ we determine the moisture consumption by $1{ }^{\circ}$ with the ratio of total water consumption to the sum of temperatures that accumulate during the growing season. According to the above calculations, EO in early maturing varieties is 370 $\mathrm{mm}$, and the sum of temperatures during this period reaches $1000{ }^{\circ} \mathrm{C}$ [5]. With these data, the coefficient of moisture consumption will be such:

$$
\mathrm{C}=370 \mathrm{~mm}: 1000{ }^{\circ} \mathrm{C}=0.370 \mathrm{~mm} /{ }^{\circ} \mathrm{C} \text {. }
$$

In early maturing varieties it is $0.370 \mathrm{~mm} /{ }^{\circ} \mathrm{C}$.

$\mathrm{SW}=0.311 \mathrm{~mm} /{ }^{\circ} \mathrm{C} \cdot 1600{ }^{\circ} \mathrm{C}=498 \mathrm{~mm}$, or $4980 \mathrm{~m}^{3} /$ ha.

Potatoes are demanding to moist soil. At the beginning and end of the growing season, plants require less moisture. In the phase period of budding-flowering, the need for moisture increases sharply, since plants have a maximum leaf area. The lack of moisture during this period leads to a decrease in yield by $50 . .60 \%$.

Precipitation during the growing season is extremely uneven, and often there is a great lack of moisture during tuber formation and tuber growth, and sometimes there are severe droughts. As a result, yields are often low and unstable over the years. Irrigation is one of the most important methods of managing the growth and development of potatoes and increasing their yield.

There are a huge number of methods of watering potato plantings. For small production volumes, the most effective today is drip irrigation, which is a network of hoses laid on the soil surface (main and distribution), through which water is supplied under pressure through holes directly to the root system of vegetating plants.

The advantages of drip irrigation: saving irrigation water (with proper operation can reach up to $50 \%$ compared to conventional methods); increased aeration of the soil (soil oxygen fully meets the need for plant roots in breathing, as the soil is not waterlogged); the formation of a branched root system, which is able to more intensively consume moisture and nutrients from the soil; the ability to directly in the root zone to make 
the necessary nutrients; since drip irrigation does not moisturize potato leaves, the possibility of spreading diseases are minimized, care and cleaning activities can be carried out at any time, as the row spacing on the beds always remain dry; there is no formation of soil crust, the structure of the soil is not destroyed. In our experiments there was small-drop irrigation.

In central Europe, early potatoes with a short growing season need moisture from mid-May to the end of June, in early varieties this period is from June to July, and later varieties from July, August and the first half of September. During the growing season of 2019, June was dry and hot.

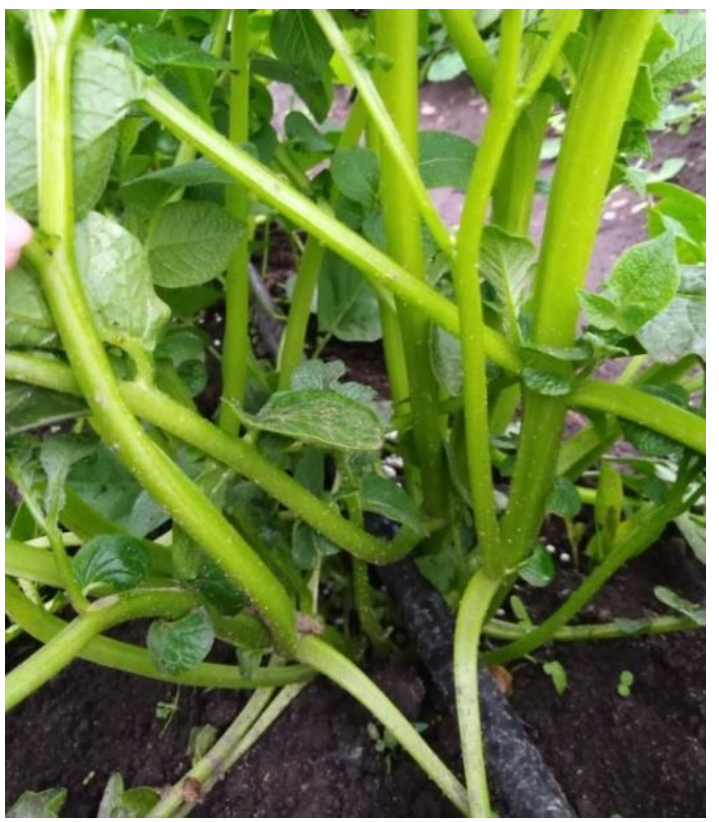

Fig. 3. Plants with small-drop watering, the number of shoots per 1 plant

Due to the uneven supply of moisture to potato plants, especially in recent years, when there were sharp temperature drops and heavy rains, alternating droughts, thunderstorms, etc. Small-drop irrigation was carried out in the experimental plot. As a result, a potato crop was obtained at an earlier date - July 15 (data are presented in table 1).

Table 1. Potato yield variety Luck, on average for 2018-2019 years

\begin{tabular}{|c|c|c|c|c|c|}
\hline \multirow[t]{2}{*}{ Option } & \multicolumn{2}{|c|}{ Cleaning 15.07. } & \multicolumn{2}{|c|}{ Cleaning 30.07. } & \multirow{2}{*}{$\begin{array}{c}\% \pm \pm \\
\text { cleaning } \\
\text { time }\end{array}$} \\
\hline & g/rast. & $\begin{array}{l}\% \pm \text { to } \\
\text { control }\end{array}$ & g/rast. & $\begin{array}{l}\% \pm \text { to } \\
\text { control }\end{array}$ & \\
\hline With irrigation & 830 & +21.2 & 1410 & +50.0 & +76.3 \\
\hline $\begin{array}{l}\text { Without } \\
\text { irrigation } \\
\text { (control) }\end{array}$ & 685 & & 940 & & \\
\hline $\mathrm{SSD}_{05}$ & 30.7 & & 52.8 & & \\
\hline
\end{tabular}

According to table 1, it can be seen that when the plant is provided with all the necessary factors, the average potato yield per plant is rather high (830 g/plant), even when harvesting on July 15 . When harvesting at the usual time for the Moscow Region
(August 1), the potato crop amounted to $1410 \mathrm{~g} / \mathrm{plant}$, without watering the crop was $940 \mathrm{~g} /$ plant (table 1).

Plants with watering formed more stems (Fig. 4-5), and as you know, there is a correlation between the number of tubers and stems or shoots formed [6-7].

The yield with watering turned out to be higher than without watering, since the average daily weight gain of tubers per bush can be $30-35 \mathrm{~g}$ according to some scientists [8] during tuber formation (for the early varieties in our zone, the month of June). In 2019, drought was observed during this period, but the temperature was favorable for photosynthesis $\left(22 \ldots 25^{\circ} \mathrm{C}\right)$, therefore, in options with watering, the yield was high.

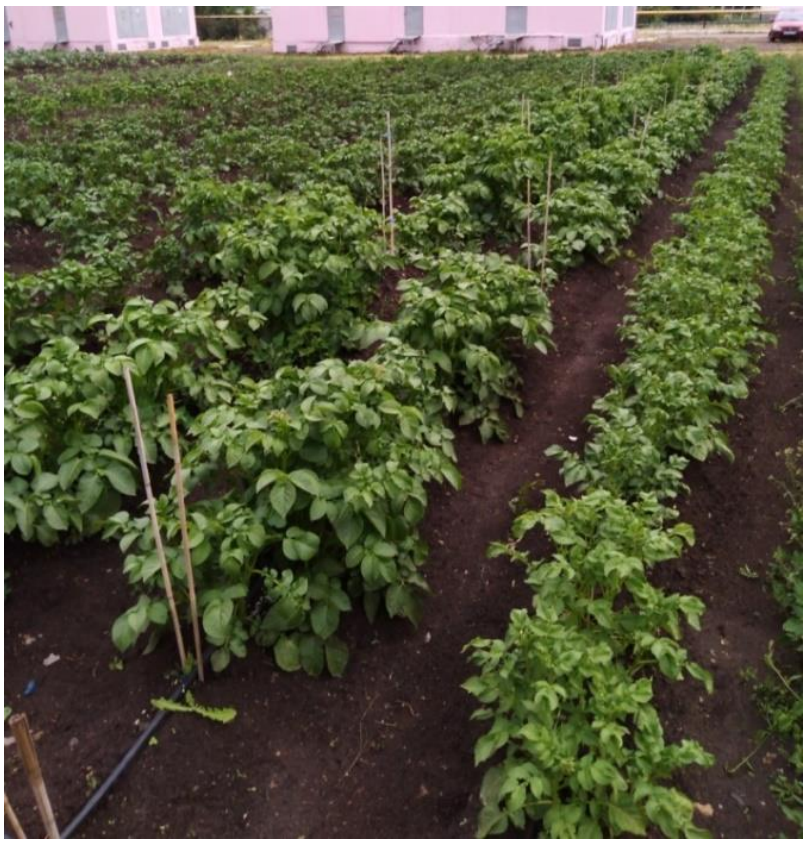

Fig. 4. Options with watering

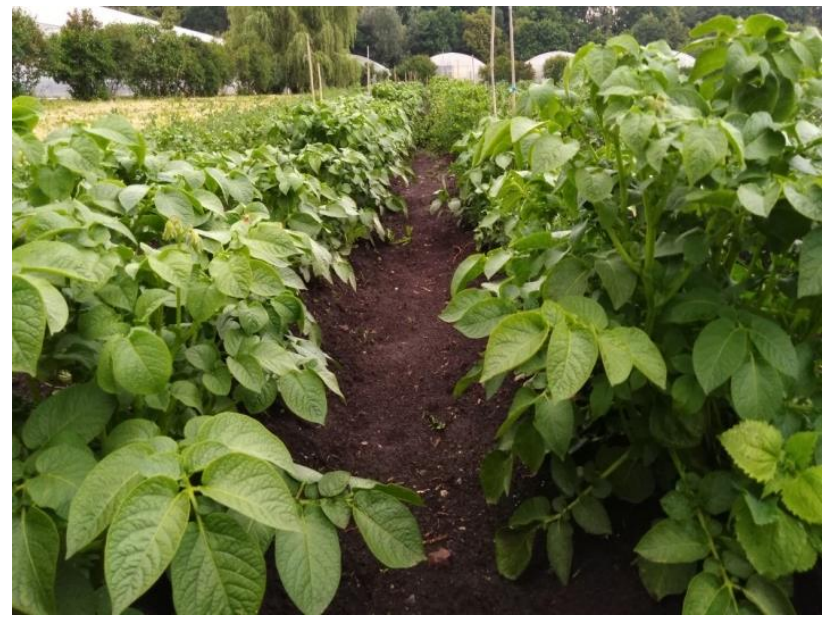

Fig. 5. Options with watering (right) and without watering (left)

When harvesting early potato production at the usual time for the Moscow Region, the yield with watering was 1,410 grams per bush. Watering is a limiting factor in such hot years.

Even short-term droughts during the budding phase reduce tuber yield by $17 \ldots 23 \%$ [3]. According to 
B.A. Pisareva (1990), in the Non-Chernozem zone, where the main areas of potato planting are concentrated, the water flow from 1 ha with a yield of $30 \mathrm{t} / \mathrm{ha}$ on loamy soil reaches $3000 \mathrm{~m}^{3}$.

Drought during the period of flowering plants and tuberization to a greater extent affects the decrease in yield than during the termination of the growth of tops. During flowering and tuberization, it negatively affects to a greater extent the number of tubers formed. With a lack of moisture during flowering, photosynthesis decreases due to increased transpiration. There is a decrease in the mass of tubers. With drought during the period of tuberization, the plant retains the ability to further growth. High moisture content at this time contributes to the growth of tubers.

The potato has a mild cuticle and low osmotic pressure - a plant of a hygrophilic type, i.e. more adapted to humid conditions [5]. It is very sensitive to sudden changes in temperature and humidity. Therefore, in many regions, maintaining optimal humidity is the main task to achieve stable and high yields, especially during the tuber formation. Potatoes need $5 \ldots 6 \mathrm{~mm}$ of water from soil moisture reserve per day.

Excess water in the soil, as well as its deficiency, negatively affects the yield of potatoes, the content of dry matter, starch in tubers decreases, and the damage to plants by fungal diseases increases. During drought, the plants cease to grow, the phallogen of the tubers dies and the cork layer becomes hard. With subsequent precipitation, tuber growth is not restored, which leads to the growth of their tops and the formation of constrictions. After a period of optimal water supply, which contributes to the strong growth of tops, even minor violations of the water regime lead to a decrease in yield [9].

In 2019, there was a hot and dry weather in the month of June, during the tuber formation, plants without watering were lower in size, the leaves are smaller. In the variant without watering, the formed stolons stopped thickening, bent and began to grow closer to the soil surface, sometimes turning into additional stems. Also various banners on stolons were formed.

When harvesting potatoes at an early date (July 15), the causative agents of early blight, late blight and other diseases do not have time to develop and harm. Potato tubers are not affected by diseases, which is important for implementation.

The tubers at harvest had a smooth surface roundedoval, with greatest transverse diameter of not less than $30 \mathrm{~mm}$, without grooves and cracks, had soft skins (peridermu). Such products are in great demand among the population and in the summer and autumn.

Providing all the necessary factors, it is possible to improve nutrition due to trace elements, the law of minimum works here. Any additional costs without taking into account the factor, which is existed in a minimum, are meaningless, cannot give the proper effect. Therefore, in the near future, the presence of moisture will be limiting in the development of productivity.

\section{Conclusion}

Thus, the use of irrigation allows increasing productivity by $50.0 \ldots 55.1 \%$, depending on the period of harvesting of tubers. The risk of potato cultivation from the uneven distribution of rainfall during the growing season and from the difference in years can be reduced by using irrigation. Early potatoes, provided all the factors are in place, have time to give a good harvest already on July 15 , and high harvest on July 30 . When harvesting in such an early time, a field is released that can be used to obtain a second crop even in our conditions.

\section{Funding}

The work was carried out in accordance with the thematic plan of research works Russian State Agrarian University - Moscow Timiryazev Agricultural Academy.

\section{Acknowledgement}

The authors would like to thank their colleague for their contribution and support to the research. They are also thankful to all the reviewers who gave their valuable inputs to the manuscript and helped in completing the paper.

\section{Conflict of Interest}

The authors have no conflict of interest to declare.

\section{References}

1. S.N. Karmanov, V.S. Serebrennikov, Potatoes (Rosagropromizdat, Moscow, 1991)

2. X. Hou, R. Li, Interactive effects of autumn tillage with mulching on soil temperature, productivity and water use efficiency of rainfed potato in loess plateau of China, Agricult. Water Managem., 224, 105747 (September 2019)

3. B.A. Pisarev, Production of early potatoes (Rosselkhoznadzor, Moscow, 1986)

4. K.K. Sarker, A. Hossain, J. Timsina et al., Yield and quality of potato tuber and its water productivity are influenced by alternate furrow irrigation in a raised bed system, Agricult. Water Managem., 224, 105750 (September 2019)

5. M.E. Dyikanova et al., The cultivation of early potatoes, a training manual (Russ. State Auton. and Agricult. Acad. named after K.A. Timiryazev, Moscow, 2019)

6. D. Shpaar, A. Bakin, D. Draeger et al., Potato (Nut, Minsk, 2004)

7. A.G. Levshin, Constructive features of the device to remove the apical shoots of potatoes, in 18th Int. Sci. Conf. "Engineering for Rural Development," 532-537 (Jelgava, Latvia, 22-24.05.2019), 
Retrieved from: www.tf.llu.lv/conference/ proceedings 2019/

8. R.B. Dwelle, Potato physiology, Chapter 2 Photosynthesis and photoassimilate partitioning, 35-38 (1985)
9. A.N. Smirnov, S. Elansky, B. Kozlovsky et al., Genotypic analysis of Russian isolates of Phytophthora infestans from the Moscow region, Siberia and far east, J. of Phytopathol., 149(10), 605-611 (2001) 